\title{
Perturbations in Cellular Bioenergetics: Childhood Obesity, Dyslipidemia, Diabetes and Hypoglycemia
}

\author{
Noura Al Hassani', Abdul-Kader Souid ${ }^{2 *}$ \\ 'Department of Pediatrics, Tawam Hospital, Alain, United Arab Emirates (UAE) \\ ${ }^{2}$ Department of Pediatrics, College of Medicine and Health Sciences - UAE University, Alain, UAE
}

\section{Article Info}

\section{Article Notes}

Received: January 05, 2020

Accepted: March 06, 2020

\section{*Correspondence:}

Abdul-Kader Souid, MD, PhD, Professor of Pediatrics, College of Medicine \& Health Sciences, UAE University, Abu Dhabi; Telephone No: +971-3-713-7429; Mobile No: +971-50-7237850; Email: asouid@uaeu.ac.ae.

(c) 2020 Hassani NA. This article is distributed under the terms of the Creative Commons Attribution 4.0 International License.

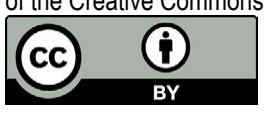

Abstract

One-third of children and adolescents are currently classified as overweight or obese. This epidemic childhood disease is the origin of adult obesity and its associated cardiovascular diseases. Dyslipidemia is also a well-recognized risk of cardiovascular disease that often starts in childhood. Breastfeeding lowers the risks of obesity and dyslipidemia later in life and it should be encouraged. Type 1 diabetes (T1D) is an immune-mediated destruction of the pancreatic islets. It is often associated with other autoimmune disorders, such as chronic lymphocytic thyroiditis and celiac disease. Children with T1D require insulin to prevent fatty acid oxidation regardless of their blood glucose level. Exercise can induce hypoglycemia in a child with T1D, as glucose utilization and insulin sensitivity increase. Thus, children with T1D need to check their blood glucose before, during, and after the activity. Type 2 diabetes (T2D) represents an insulin deficiency due to obesity and genetic susceptibility; glucose is overproduced by the liver and underused by the muscles. Thus, healthy diet and regular exercise are the recommended remedies for this condition.

\section{Obesity}

Approximately one-third of children and adolescents are classified as either overweight or obese ${ }^{1}$. This early problem of excess fat causes adult obesity (an example of the childhood origin of adult diseases), subclinical inflammation, type 2 diabetes (T2D), insulin resistance, dyslipidemia, hypertension, endothelial dysfunction, atherosclerosis, metabolic syndrome, and susceptibility to cancer and other numerous complications ${ }^{2}$. Lead causes of this epidemic disease include genetic susceptibility, family influences, access to high-calorie foods, and sedentary lifestyle (e.g., high screen time) ${ }^{3}$.

Intra-abdominal fat (abdominal/ central obesity) conveys a great metabolic risk. Therefore, the waist-to-height ratio (optimal, <0.5), waist circumference (measured at the level of the umbilicus), and waist-to-hip ratio have become useful markers for risks of obesityrelated cardiovascular diseases. Starting at 2 years of age, the BMI (body mass index) can also be used to screen for childhood adiposity (Table 1).

Metabolic syndrome occurs in most individuals with significant obesity. Insulin resistance is central to the development of this constellation of findings and is implicated in its pathogenicity. The syndrome represents a combination of central obesity, hyperglycemia, hypertension, and dyslipidemia (increased triglycerides and decreased HDL-C [high-density lipoprotein cholesterol]). It predicts cardiovascular disease, T2D, and nonalcoholic fatty liver disease (increased alanine aminotransferase [ALT]) in adults. The 
Table 1. Summary of obesity information.

\begin{tabular}{|l|l|}
\hline Excess body fat & $\begin{array}{l}\text { For children, a BMI at } 85 \text { th to } 94 \text { th centiles is overweight and at } 95^{\text {th }} \text { centile obesity. } \\
\text { For adults, a BMI at } 25 \mathrm{~kg} / \mathrm{m}^{2} \text { is overweight and at } 30 \mathrm{~kg} / \mathrm{m}^{2} \text { obesity. }\end{array}$ \\
\hline Metabolic syndrome & Insulin resistance, central obesity, hyperglycemia, hypertension, $\uparrow$ triglycerides, $\downarrow \mathrm{HDL}-\mathrm{C}$. \\
\hline Bariatric surgery & $\mathrm{SMR} 4-5$ plus BMI of $40 \mathrm{~kg} / \mathrm{m}^{2}$ or $35 \mathrm{~kg} / \mathrm{m}^{2}$ with obesity-related complications. \\
\hline Investigations & $\begin{array}{l}\text { Screening for T2D, dyslipidemia, insulin resistance, ALT, hypertension, obstructive sleep apnea, polycystic ovarian syndrome, } \\
\text { genetic testing (young children with extreme obesity). Short stature or delayed puberty requires further investigation. }\end{array}$ \\
\hline
\end{tabular}

International Diabetes Federation recommends using the adult definition of metabolic syndrome for children $\geq 10$ years ${ }^{4}$. Insulin insensitivity is evident in children with $\geq 2$ features of the metabolic syndrome ${ }^{5}$.

The workup for obesity may include screening for T2D, dyslipidemia, insulin resistance (acanthosis), hypertension, nonalcoholic fatty liver disease (ALT), obstructive sleep apnea, and polycystic ovarian syndrome. Genetic testing is typically offered for young children with extreme obesity. The presence of short stature or delayed puberty requires searching for additional causes of obesity.

The polycystic ovary syndrome (PCOS1, MIM\#184700) is a heterogeneous disorder that affects about $10 \%$ of reproductive-age females. There are multiple potential factors involved in the pathogenesis of PCOS including obesity and insulin resistance. The diagnostic criteria include irregular menses/oligomenorrhea plus clinical (e.g., hirsutism and acne) or biochemical hyperandrogenism. The increased androgen is from the ovaries and adrenal glands. Elevated total and/or free testosterone are characteristics of PCOS and originate from the ovaries. Dehydroepiandrosterone sulfate (DHEA-S) originates from the adrenal glands, and it is elevated in only half of the patients ${ }^{6}$.

Treatment of obesity includes healthy diet, slow weight reduction, regular exercise, and pharmacological therapy (optional). These interventions are best accomplished through a family-based behavioral therapy to install healthy living choices in younger people. Furthermore, proper counseling of the family to choose healthier eating habits and to positively influence healthy habits in children and adolescents is essential. Water and whole fruits should substitute fruit juices and sweetened drinks. Children should spend $\geq 20$ min per day in vigorous activity (optimal, 60-min exercise daily).

It is worth noting that a $5 \%$ reduction in BMI results in significant metabolic improvements. It is also important to note that psychological problems should be managed before starting a weight reduction program. Very-low-calorie diets $(\leq 1,000$ kilocalories per day $)$ cause micronutrient deficiency, thus, nictitating regular monitoring and proper micronutrient (e.g., vitamin B12 and minerals) supplementations.

Men with obesity and hypogonadism are considered for testosterone therapy in addition to lifestyle intervention. Testosterone in these individuals may result in a weight loss and metabolic improvement.

Metformin is approved for T2D in children $\geq 10$ years of age. The drug is also used (off-label) for weight loss. In several trials, metformin causes a modest reduction in BMI ${ }^{1}$. Orlistat (PubChem Compound ID\#3034010, lipase inhibitor) is an approved medication for obesity in adolescents $\geq 12$ years of age. The drug, however, should be stopped for an insignificant weight loss at 12 weeks. Bariatric surgery is also recommended for refractory obesity if the adolescent is at sexual maturity rating (SMR) 4 to 5 and a BMI of $40 \mathrm{~kg} / \mathrm{m}^{2}$ or $35 \mathrm{~kg} / \mathrm{m}^{2}$ with complications. Prebiotics are indigestible oligosaccharides and long complex polysaccharides, which enhance the proliferation of probiotic bacteria, such as Bifidobacteria species. Their clinical usefulness in childhood obesity is promising ${ }^{7}$. It is worth noting that the nutritional values of fibers from whole grains, used as prebiotic substrates by the gut microbiome, convey cardiometabolic health benefit.

Breastfed infants have a lower risk of overweight/obesity later in life than those who are formula fed. Therefore, the American Academy of Pediatrics recommends exclusive breastfeeding for at least 6 months, followed by continued breastfeeding for at least 1 year ${ }^{16-20}$.

\section{Dyslipidemia}

Dyslipidemia is a well-recognized risk of cardiovascular disease, which often starts in childhood. Treating children with dyslipidemia may reduce the acceleration of atherosclerosis and the risk of premature cardiovascular disease (another example of childhood origin of the adult disease). Interventions include encouraging breastfeeding, low intake of saturated fat (starting at 1 year), and regular physical activity.

The 2011 Expert Panel on Integrated Guidelines for Cardiovascular Health and Risk Reduction in Children and Adolescents recommends universal screening (using nonfasting LDL [low-density lipoproteins] or fasting lipid panel) at 9 to $11 \mathrm{y}$ and at 17 to $21 \mathrm{y}^{8}$. Nearly 1 in 3 children screened at 9 to $11 \mathrm{y}$ have a borderline or high cholesterol level. Children with total cholesterol $>5.18$ $\mathrm{mmol} / \mathrm{L}, \mathrm{HDL}<1.17 \mathrm{mmol} / \mathrm{L}$, and $\mathrm{LDL}>3.37 \mathrm{mmol} / \mathrm{L}$ are at risk of early coronary artery disease. The current evidence, however, is insufficient to assess the benefit of screening 
Table 2. Summary of dyslipidemia.

\begin{tabular}{|l|l|}
\hline Universal screening & Nonfasting $\mathrm{LDL}$ or fasting lipid panel at 9 to $11 \mathrm{y}$ and at 17 to $21 \mathrm{y}$. \\
\hline$\uparrow$ Risk of coronary artery disease & A total cholesterol $>5.18 \mathrm{mmol} / \mathrm{L}, \mathrm{LDL}>3.37 \mathrm{mmol} / \mathrm{L}$, and $\mathrm{HDL}<1.17 \mathrm{mmol} / \mathrm{L}$. \\
\hline Indications for statin treatment & $\begin{array}{l}\text { (1) } \mathrm{LDL} \geq 190 \mathrm{mg} / \mathrm{dL}(>4.9 \mathrm{mmol} / \mathrm{L}) ;(2) \mathrm{LDL} \geq 160 \mathrm{mg} / \mathrm{dL}(>4.1 \mathrm{mmol} / \mathrm{L}) \text { plus positive family history } \\
\text { of early coronary artery disease; or (3) } \mathrm{LDL} \geq 130 \mathrm{mg} / \mathrm{dL}(>3.4 \mathrm{mmol} / \mathrm{L}) \text { plus diabetes. }\end{array}$ \\
\hline
\end{tabular}

for lipid disorders before $20 \mathrm{y}$. Thus, proper counseling of the family is necessary prior to lipid screening ${ }^{8}$. Statin has been advocated in children $\geq 10$ years of age with significant dyslipidemia not responding to lifestyle changes (Table 2). It is important to emphasize that prevention of dyslipidemia needs an improved physical activity and a healthy diet rich in soluble fiber $\beta$-glucan and vegetable phytosterols (plant sterols).

\section{Type 1 Diabetes (T1D)}

T1D is an immune-mediated destruction of the pancreatic islets, as $>90 \%$ of affected children show autoantibodies to the pancreatic islet (islet cell cytoplasm), insulin, and/or glutamic acid decarboxylase (GAD). Consistently, common human leukocyte antigens (HLA) include DR3, DR4, and DQ. Low expression of islet cell antigens in the thymus may promote specific autoimmune CD4+ T cells ${ }^{9}$. The disease affects one of 300 school-age children, peaking at 5 to $7 \mathrm{y}$. It is diagnosed when about $90 \%$ of the beta-cells are destroyed. The concordance rate in identical twins is $<50 \%$ ( $100 \%$ for T2D).

T1D is associated with other autoimmune disorders, such as chronic lymphocytic thyroiditis $25 \%$ of patients; $1 / 3$ have detectable anti-thyroid antibodies and 1/10 have hypothyroidism) and celiac disease (5\% of patients). The American Diabetes Association recommends screening for thyroid disease with thyroid antibody (thyroid peroxidase antibodies and thyroglobulin antibodies) and TSH (thyroid stimulating hormone) at diagnosis and every $1-2 \mathrm{y}^{10}$. Celiac disease typically presents with abdominal pain and poor weight gain; its screening tests are 'tissue transglutaminase (TTG) IgA antibody' and endomysial IgA antibody; abnormal results indicate the need for small intestinal biopsy. All patients with celiac disease have DQ2 or DQ8 (of note, the prevalence of these haplotypes in the population is about 30\%). The American Diabetes Association recommends screening for celiac disease at diagnosis, $2 \mathrm{y}$ later, and then every $5 \mathrm{y}^{10}$. Other associated autoimmune disorders include primary adrenal insufficiency (Addison disease, $<1 \%$ ), premature ovarian failure, vitiligo, alopecia areata, and pernicious anemia ${ }^{11}$.

Long-term complications of T1D include retinopathy ( $10 \%$ after $10 \mathrm{y} ; 50 \%$ after $20 \mathrm{y}$ ), nephropathy (50\% after $25 \mathrm{y}$; ACE [angiotensin-converting-enzyme] inhibitors may ameliorate nephropathy), neuropathy, and delayed puberty. Adult height is typically reached.

Children with T1D require insulin to prevent fatty acid oxidation regardless of the blood glucose level. Thus, their treatment involves a 'rapid-acting insulin' prior to or up to 30 min after meals, using a carbohydrate count and a sliding scale dosing based on blood glucose reading; e.g., Lispo, Aspart or Glulisine at 1 unit/15 g carbohydrate for children and 1 unit/20 g for infants. A 'long-acting insulin' to maintain a proper basal level is also needed; e.g., Glargine at 0.5 unit $/ \mathrm{kg}$ once daily. The diabetic diet should include $15 \%$ protein, $30 \%$ fat, and $55 \%$ carbohydrate (from a complex sugar, such as starch). Refined sugar should be avoided.

Blood glucose should be monitored at least 4 times daily. Urine ketones should be checked if blood glucose $>240 \mathrm{mg} /$ $\mathrm{dL}$ (13.5 mmol/L) or during emesis. Positive urine ketone signifies lipolysis due to a lack of insulin. In addition, blood glucose needs to be checked between 12am and 3am and between 5am and 9am to adjust the long-acting insulin dose. Somogyi effect is hyperglycemia that occurs between 5 am and 9am with a preceding hypoglycemia. Dawn effect is normal hyperglycemia between 5am and 9am without a preceding hypoglycemia (due to the growth hormone release during sleep).

The American Diabetes Association recommends blood glucose measurements before meals and snacks, at bedtime, before exercise, and before driving. Prandial insulin should be taken before meals to best match the onset of insulin action with rising blood glucose. The $\mathrm{HbA}_{1 \mathrm{c}}$ goal is $<7.5 \%$ for all pediatric patients ${ }^{10}$. Achieving a good glycemic control is important in preventing long-term complications. Carbohydrate counting, avoiding simple sugars, and eating a well-balanced diet are contributors to a good glycemic control. Eating low- or non-carbohydrate snacks can obviate the need for an insulin injection to cover the snack.

Hypoglycemia in T1D is defined as plasma glucose $<70$ $\mathrm{mg} / \mathrm{dL}(<3.9 \mathrm{mmol} / \mathrm{L})$. Treatment implements the "rule of 15s": $15 \mathrm{~g}$ of fast-acting carbohydrate (1/2 cup of juice or regular soda, 1 cup of milk, or 3-4 glucose tablets); plasma glucose should be checked 15 min later. This approach (treatment and glucose check) should be repeated if the level remains $<70 \mathrm{mg} / \mathrm{dL}$. If the next meal will not be eaten within the next $30 \mathrm{~min}$, a small snack of complex carbohydrate, fat, and protein should be eaten to help sustain blood glucose. For more severe hypoglycemia and the inability to take oral glucose, glucagon is given intramuscularly or subcutaneously. Every patient with diabetes who takes insulin should have a glucagon emergency kit. 
Exercise can induce hypoglycemia in a child with T1D, as glucose utilization and insulin sensitivity increase. Thus, children need to check their blood glucose before, during, and after the activity. Necessary adjustments may include less short-acting insulin at the previous meal or a snack prior to or during the activity. The blood glucose should be checked hourly if the exercise is long.

Diabetic ketoacidosis (DKA) is a short-term complication of T1D. It occurs as insulin deficiency reduces cellular glucose uptake and augments counter-regulatory hormones (glucagon, epinephrine, and growth hormone). These events increase gluconeogenesis and glycogenolysis. Free fatty acids are released from the adipose tissue and convert via beta-oxidation into ketoacids (acetoacetate and beta-hydroxybutyrate), causing high anion gap metabolic acidosis. Hyperglycemia causes glucosuria when it exceeds the usual renal threshold of about 180 $\mathrm{mg} / \mathrm{dL}(10 \mathrm{mmol} / \mathrm{L})$, which together with hyperketonemia causes osmotic diuresis, dehydration and obligatory loss of electrolytes, often aggravated by vomiting associated with severe ketosis ${ }^{12}$.

DKA is treated by an initial $0.9 \% \mathrm{NaCl}$ bolus $(10 \mathrm{~mL} /$ $\operatorname{kg}$ over 1 to $2 \mathrm{~h}$ ). This phase is followed by a correction of the remaining fluid deficit (typically, $\geq 7.5 \%$ deficit) over 48 to $72 \mathrm{~h}$, in addition to the daily maintenance fluid requirement (as long as the child is NPO). More rapid fluid administration may be indicated in children in hypovolemic shock; however, the fluid approach must be balanced against potential cerebral edema. Thus, the first therapeutic intervention is a slow rehydration over 1 to $2 \mathrm{~h}$ with $0.9 \% \mathrm{NaCl}$. Insulin is started 1 to $2 \mathrm{~h}$ after fluid has begun, as the usual volume deficit requires initial partial correction before the insulin.

Encephalopathy from cerebral edema is a life- threatening complication of DKA. In response to impaired protein, fat, and carbohydrate metabolism, neurons accumulate "organic idiogenic osmoles" to maintain intracellular volume. This process of 'osmolar equilibrium' is known as 'cerebral osmoregulation'. Rapid hydration and insulin administration lower plasma glucose $(\downarrow$ serum osmolarity), which leads to a rapid $\uparrow$ cell volume (cerebral edema). Hypotonic solutions further aggravate these events $^{13}$.

It is worth noting here that " $0.9 \% \mathrm{NaCl}^{\circ}$ has an osmolality of $286 \mathrm{mmol} / \mathrm{L}$. This solution will lower the serum osmolality in children with hyperosmolar hyperglycemic state (HHS) or diabetic ketoacidosis. The osmolality of $0.9 \% \mathrm{NaCl}$ is calculated as: [154 mmol/L $\left.\mathrm{Na}^{+}+154 \mathrm{mmol} / \mathrm{L} \mathrm{Cl}^{-}\right]$x 0.93 (the osmotic coefficient, a correction for non-ideal solutions).

\section{Type 2 Diabetes (T2D)}

In T2D (relative insulin deficiency often associated with obesity and a strong family history of the same), glucose is overproduced by hepatocytes and underused by other cells, especially muscles (the largest tissue regulated by insulin ${ }^{14}$. Normal fasting plasma glucose is $<100 \mathrm{mg} / \mathrm{dL}$ $(<5.6 \mathrm{mmol} / \mathrm{L})$. T2D and prediabetes states are defined as shown in Table 3. T2D is typically associated with high BMI and acanthosis (a skin hyperpigmentation associated with insulin resistance), as obesity is a significant predisposing factor. The mean age at diagnosis is at the onset of puberty $(\sim 13 \mathrm{y})$. The disease is managed with a healthy diet and regular exercise. Insulin and/or metformin may also be required.

Despite a good glycemic control, pregnant women who have diabetes have an increased prevalence of ýcongenital malformation; thus, a second-trimester fetal ultrasonography is required. Potential fetal anomalies

Table 3. Definitions of T2D (a combination of insulin resistance and relative insulin deficiency) and prediabetes states

\begin{tabular}{|c|c|c|c|c|}
\hline & $\begin{array}{l}\text { Fasting plasma glucose } \\
\text { (no calories for } 8 \mathrm{~h})^{1}\end{array}$ & $\begin{array}{l}\text { Random plasma } \\
\text { glucose }\end{array}$ & $\begin{array}{c}\text { Glucose tolerance test (at } 2 \\
\mathrm{~h} \text { after } 75 \mathrm{~g} \text { sugar) }\end{array}$ & Hemoglobin A1c (HbA1c) ${ }^{2}$ \\
\hline Normal & $\begin{array}{c}<100 \mathrm{mg} / \mathrm{dL} \\
<5.6 \mathrm{mM}\end{array}$ & $\begin{array}{l}<140 \mathrm{mg} / \mathrm{dL} \\
<7.8 \mathrm{mmol} / \mathrm{L}\end{array}$ & $\begin{array}{l}<140 \mathrm{mg} / \mathrm{dL} \\
<7.8 \mathrm{mmol} / \mathrm{L}\end{array}$ & $\begin{array}{c}<5.7 \% \\
<39 \mathrm{mmol} \text { glucose } / \mathrm{mol} \text { hemoglobin }\end{array}$ \\
\hline Prediabetes & $\begin{array}{l}100 \text { to } 125 \mathrm{mg} / \mathrm{dL} \\
5.6 \text { to } 7.0 \mathrm{mmol} / \mathrm{L}^{3}\end{array}$ & $\begin{array}{l}140 \text { to } 200 \mathrm{mg} / \mathrm{dL} \\
7.8 \text { to } 11.0 \mathrm{mmol} / \mathrm{L}\end{array}$ & $\begin{array}{l}140 \text { to } 200 \mathrm{mg} / \mathrm{dL} \\
7.8 \text { to } 11.0 \mathrm{mmol} / \mathrm{L}^{4}\end{array}$ & $\begin{array}{c}5.7 \% \text { to } 6.4 \% \\
39 \text { to } 47 \mathrm{mmol} \text { glucose } / \mathrm{mol} \text { hemoglobin }\end{array}$ \\
\hline $\mathrm{T} 2 \mathrm{D}^{5}$ & $\begin{array}{l}\geq 126 \mathrm{mg} / \mathrm{dL} \\
\geq 7.0 \mathrm{mmol} / \mathrm{L}\end{array}$ & $\begin{array}{l}\geq 200 \mathrm{mg} / \mathrm{dL} \\
\geq 11.0 \mathrm{mmol} / \mathrm{L}\end{array}$ & $\begin{array}{l}\geq 200 \mathrm{mg} / \mathrm{dL} \\
\geq 11.0 \mathrm{mmol} / \mathrm{L}\end{array}$ & $\begin{array}{c}\geq 6.5 \% \\
\geq 48 \mathrm{mmol} \text { glucose } / \mathrm{mol} \text { hemoglobin }\end{array}$ \\
\hline \multicolumn{5}{|c|}{ 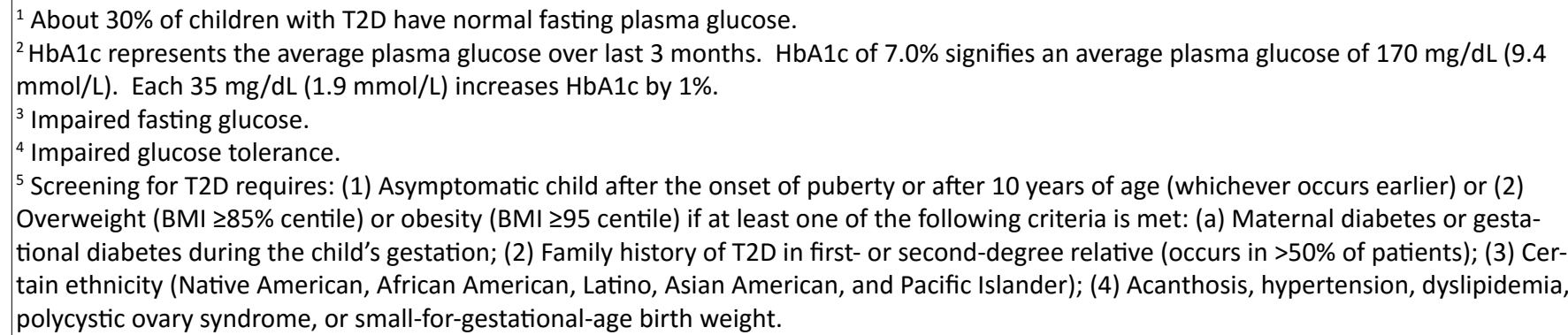 } \\
\hline
\end{tabular}


include the heart (transposition, truncus, and hypoplastic left heart), central nervous system (e.g., neural tube defects), and chromosomal aberrations. Other complications include macrosomia, hypoglycemia, jaundice, and lung immaturity ${ }^{14}$.

Another recognized complication of $\mathrm{T} 2 \mathrm{D}$ is a hyperosmolar hyperglycemic state (HHS), which carries significant mortality. This entity is associated with severe hyperglycemia and dehydration (about twice the fluid loss in diabetic ketoacidosis). Diagnostic criteria include: (1) Plasma glucose $>600 \mathrm{mg} / \mathrm{dL}(>33.3 \mathrm{mmol} / \mathrm{L}),(2)$ Venous $p \mathrm{H}>7.25$ or arterial $p \mathrm{H}>7.30$, (3) Serum bicarbonate $>15 \mathrm{mmol} / \mathrm{L}$, (4) Only small ketonuria or absent-to-mild ketonemia, (5) Serum osmolality $>320 \mathrm{mOsm} / \mathrm{kg}$, and (6) Altered consciousness or seizures ${ }^{13}$. Treatment includes $0.9 \% \mathrm{NaCl}$ (e.g., $10-20 \mathrm{~mL} / \mathrm{kg}$ over $1 \mathrm{~h}$ ), which can be repeated if necessary to restore tissue perfusion (e.g., a capillary refill time $\leq 2 \mathrm{sec}$ ). Insulin is withheld until fluid resuscitation is satisfactory and serum glucose ceases to decrease from rehydration alone. Insulin infusion is then started at 0.025-0.05 units $/ \mathrm{kg} / \mathrm{h}$, and titrated to decrease plasma glucose of $50-75 \mathrm{mg} / \mathrm{dL} / \mathrm{h}$ (2.7-4.1 mmol/L/h). It is worth noting that about $20 \%$ of children with T2D have behavioral problems and may be taking medications associated with insulin resistance, such as atypical antipsychotics (e.g., perphenazine). The transition from insulin to metformin is attempted when plasma glucose is $<250 \mathrm{mg} / \mathrm{dL}(<13.9 \mathrm{mmol} / \mathrm{L})$.

\section{Hypoglycemia}

Exaggerated insulin secretion from pancreatic beta cells in the first few hours or days of life results in neonatal hypoglycemia, which can be transient or permanent (persistent). Transient hyperinsulinemia may result from maternal dextrose infusion during labor, maternal intake of a hypoglycemic agent, maternal diabetes (infant born to a diabetic mother), preterm neonate, small-for-gestationalage neonate, and neonatal asphyxia. Congenital causes, such as Beckwith-Wiedemann syndrome (MIM\#130650), mosaic Turner syndrome, and Costello syndrome (MIM\#218040, 'congenital myopathy with excess of muscle spindles') produce hyperinsulinemic hypoglycemia that lasts for days or weeks ${ }^{15,16}$.

Persistent hyperinsulinemic hypoglycemia of infancy may result from various pathologic variants (Table 4), such as hyperinsulinemic hypoglycemia, familial, 1 (HHF1, MIM\#256450) that results from variants involving the 'ATP-binding cassette, subfamily C, member 8; $A B C C 8$ ' gene (MIM\#600509). ABCC8 encodes for SUR1 subunit of the pancreatic beta cell 'ATP-sensitive potassium channel', K(ATP), which physiologically reduces insulin secretion. Of note, sulfonylureas (a class of oral hypoglycemic agents) promote insulin secretion by inhibiting the conductance of K(ATP). Clues that support persistent hyperinsulinemic hypoglycemia of infancy include high glucose requirement, response to glucagon (a rise of $>30 \mathrm{mg} / \mathrm{dL}$ [ $>1.7 \mathrm{mmol} / \mathrm{L}]$ ), measurable insulin at the time of hypoglycemia, and low $\beta$-hydroxybutyrate and free fatty acid levels (insulininduced suppression of fatty acid oxidation) ${ }^{17}$. The hypoglycemia in panhypopituitarism (requires growth hormone and corticosteroid) and disorders of fatty acid synthesis (requires carnitine), on the other hand, does not show high glucose requirement and does not resolve with glucagon $^{18}$.

Neonatal hypoglycemia is the predominant presenting symptom of congenital hypopituitarism. It is associated with gonadotropin deficiency, such as micropenis (a stretched phallic length of $<2.0$ to $2.5 \mathrm{~cm}$ ) and cryptorchidism. These clinical findings with the presence of hypoglycemia make other anterior pituitary hormone deficiencies likely. Other clinical features of congenital hypopituitarism (caused by the effects of anterior pituitary hormone deficiencies) include post-dates gestation, breech position, poor feeding, hypotonia, prolonged jaundice, and cholestasis. Midline defects may be present. The presence of wandering nystagmus suggests sept optic dysplasia (MIM\#182230). Diabetes insipidus is evident if the posterior pituitary hormone vasopressin is deficient (MIM\#241540). In addition to hypoglycemia, laboratory evaluation may reveal hyponatremia due to central adrenal insufficiency or hypernatremia due to diabetes insipidus. Central adrenal

Table 4. Genetic causes of persistent hyperinsulinemic hypoglycemia of infancy.

\begin{tabular}{|l|l|}
\hline \multicolumn{1}{|c|}{ Genes } & \multicolumn{1}{c|}{ Diseases } \\
\hline $\begin{array}{l}\text { ATP-binding cassette, subfamily C, member 8; ABCC8 (MIM\#600509) - } \\
\text { AD or AR }\end{array}$ & Hyperinsulinemic hypoglycemia, familial, 1; HHF1 (MIM\#256450) \\
\hline $\begin{array}{l}\text { Potassium channel, inwardly rectifying, subfamily J, member 11; KCNJ111 } \\
\text { (MIM\#600937) - AR }\end{array}$ & Hyperinsulinemic hypoglycemia, familial, 2; HHF2 (MIM\#601820) \\
\hline Glucokinase; GCK (MIM\#138079) - AD & Hyperinsulinemic hypoglycemia, familial, 3; HHF3 (MIM\#602485) \\
\hline 3-Hydroxyacyl-CoA dehydrogenase; HADH (MIM\#601609) - AR & Hyperinsulinemic hypoglycemia, familial, 4; HHF4 (MIM\#609975) \\
\hline Insulin receptor; INSR (MIM\#147670) - AD & Hyperinsulinemic hypoglycemia, familial, 5; HHF5 (MIM\#609968) \\
\hline Glutamate dehydrogenase 1; GLUD1 (MIM\#138130) - AD & Hyperinsulinemic hypoglycemia, familial, 6; HHF6 (MIM\#606762) \\
\hline $\begin{array}{l}\text { Solute carrier family 16 (monocarboxylic acid transporter), member 1; } \\
\text { SLC16A1 (MIM\#600682) - AD }\end{array}$ & Hyperinsulinemic hypoglycemia, familial, 7; HHF7 (MIM\#610021) \\
\hline AD, autosomal recessive; AD, autosomal dominant; MIM, Mendelian Inheritance in Man. \\
\hline
\end{tabular}


insufficiency results in low serum cortisol. Relative thyroid-stimulating hormone (TSH) deficiency results in a low free thyroxine level with a low or inappropriately normal TSH level. A random growth hormone (GH) level is a useful measure in the first week of life. Thereafter, insulin-like growth factor-1 (IGF-1) and insulin-like growth factor binding protein-3 (IGFBP3) are more appropriate measures of GH status and will be low in hypopituitarism. Magnetic resonance imaging (MRI) of the brain is indicated in children with hypopituitarism. An anatomic abnormality is likely with congenital hypopituitarism, such pituitary stalk interruption syndrome (the triad of hypoplastic anterior pituitary, absent pituitary stalk, and ectopic posterior pituitary) and sept optic dysplasia (optic nerve hypoplasia and absent corpus callosum or septum pellucidum).

As noted above, hypoglycemia in T1D is defined as plasma glucose $<70 \mathrm{mg} / \mathrm{dL}(<3.9 \mathrm{mmol} / \mathrm{L})$. Its treatment includes a fast-acting carbohydrate (e.g., juice, regular soda, milk, or glucose tablets); plasma glucose should be checked 15 min later. This treatment and glucose check are repeated if the glucose level is still $<70 \mathrm{mg} / \mathrm{dL}$. For more severe hypoglycemia and the inability to take oral glucose, glucagon is given intramuscularly or subcutaneously. Every patient with diabetes who takes insulin should have a glucagon emergency kit.

Conscious children with hypoglycemia are treated with $15 \mathrm{~g}$ oral glucose; the blood glucose should be checked after $15 \mathrm{~min}$. Unconscious children require glucagon (1 mg, intramuscularly), which has an adverse event of emesis and a limitation of the need for adequate glycogen stores. Alternative treatment is intravenous $10 \%$ glucose at $2-4$ $\mathrm{mL} / \mathrm{kg}$ (preferred if the child has intravenous access). Long-term treatment of hypoglycemia is diazoxide (5-15 $\mathrm{mg} / \mathrm{kg} /$ day in 2 or 3 divided doses), while octreotide is an option for children who fail diazoxide. Pancreatectomy is considered if medical treatment fails.

Diazoxide is a K-channel activator; it inhibits the voltage- gated calcium channel. It is used as a (1) Vasodilator, (2) Decreased insulin secretion, and (3) Cognitive enhancer (allosteric modulator of AMPA [ $\alpha$-amino-3-hydroxy-5methyl-4-isoxazolepropionic acid] and kainite [ionotropic] receptors). Octreotide is an octapeptide (eight amino acids) that mimics natural somatostatin (growth hormone-inhibiting hormone that inhibits insulin and glucagon secretion); it is a more potent inhibitor of growth hormone, glucagon, and insulin than the natural hormone somatostatin.

\section{Supplementary information}

Glucose is the sole metabolic fuel for the brain (except during extended starvation). Thus, the function of the brain depends on a continuous supply of glucose. Plasma 'fatty acids' are bound to albumin and, hence, they do not cross the blood-brain barrier. Ketones (products of fatty acid oxidation) can supply fuel to the brain during starvation.

Cellular glucose uptake is mediated by several glucose transporters (GLUT). GLUT1 and GLUT3, present in all cells (including the brain), have a $\mathrm{K}_{\mathrm{M}}$ value (an inverse measure of the glucose affinity to the receptor, defined as 'glucose concentration at half maximum transport rate') of 1 to 2 $\mathrm{mM}$ (compared to the normal blood glucose of 3.6 to 6.1 $\mathrm{mM}$ ). Thus, sufficient glucose supply to the brain continues unless blood glucose drops $<2 \mathrm{mM}(36 \mathrm{mg} / \mathrm{dL})$, the $\mathrm{K}_{\mathrm{M}}$ of GLUT3. The $\mathrm{K}_{\mathrm{M}}$ for GLUT2 is 15 to $20 \mathrm{mM}$, allowing glucose transport only when blood glucose is abundant. This transporter supports glucose-stimulated insulin secretion in pancreatic beta cells and glycogen and fat syntheses in hepatocytes. Thus, GLUT2 ensures insulin is secreted only when glucose is abundant (e.g., after meals).

In beta cells, glucose metabolism raises cellular ATP, which closes the ATP-sensitive $\mathrm{K}^{+}$channels and opens the $\mathrm{Ca}^{2+}$ channels. These processes result in fusing insulin vesicles into the cell membrane and release of insulin to the blood. Insulin then increases the expression of GLUT4 $\left(\mathrm{K}_{\mathrm{M}}=5 \mathrm{mM}\right)$, which transports glucose into muscles and fat cells (Table 5).

Table 5. The anabolic hormone insulin.

\begin{tabular}{|l|l|}
\hline \multicolumn{2}{|c|}{ Actions of Insulin } \\
\hline $\begin{array}{l}\text { Promotes synthesis and storage of glycogen and triglyceride, } \\
\text { and inhibits their metabolism. }\end{array}$ & Anabolic effects. \\
\hline Suppresses gluconeogenesis. & \\
\hline $\begin{array}{l}\text { Recruits glucose transporters (e.g., GLUT4) from intracellular } \\
\text { vesicles to plasma membrane. }\end{array}$ & Stimulating glucose transport into myocytes and adipocytes. \\
\hline Consequences of Absent Insulin & These processes require insulin. \\
\hline$\downarrow$ Liver uptake \& metabolism of glucose. & $\begin{array}{l}\text { OA is a glycolytic metabolite that binds acetyl CoA to form citrate in the citric } \\
\text { acid cycle. OA drives the citric acid cycle. }\end{array}$ \\
\hline$\downarrow$ Liver synthesis of oxaloacetate (OA). & Acetyl CoA will fail to enter the citric acid cycle as it requires OA. \\
\hline$\uparrow$ Liver acetyl CoA from fatty acid oxidation & This metabolite is a moderately strong acid. \\
\hline Acetyl CoA forms acetoacetate. & This metabolite is an energy source. \\
\hline Acetoacetate converts to hydroxybutyrate. & This metabolite is responsible for the typical smell of diabetic ketoacidosis. \\
\hline Acetoacetate also converts to acetone. &
\end{tabular}


In a normal cell, insulin binds to a receptor. The complex then dimerizes, auto-phosphorylates on tyrosine residues, and recruits binding sites for IRS (insulinreceptor substrates). Phosphorylated IRS activates PI3K (phosphatidylinositol 3-kinases), which converts PIP2 (phosphorylating phosphatidylinositol-4, 5-bisphosphate) to PIP3 (phosphatidylinositol-3, 4, 5-triphosphate). PIP3 activates PDK (phosphoinositide-dependent kinase 1) and Akt (protein kinase B) facilitating the translocation of GLUT4 vesicles to the cell membrane. This leads to the absorption of glucose from the blood. Insulin activates glycogen synthase.

Glycolysis is the anaerobic reaction that forms two pyruvate, two ATP, and two NADH from one glucose. NAD ${ }^{+}$ (essential for driving glycolysis) is then generated by the reduction of pyruvate to lactate by lactate dehydrogenase (LDH). Aerobically, $\mathrm{NAD}^{+}$is generated by the oxidation in the mitochondrial respiratory chain.

Glycolysis is highly regulated. Phosphofructokinase (PFK), the committed step (phosphorylates fructose 6-phosphate to fructose 1,6-bisphosphate), is allosterically inhibited by ATP and citrate (signifying a high-energy state) and stimulated by AMP (signifying a low-energy state). The main regulator of glycolysis in the liver is fructose 2,6-bisphosphate. When blood glucose is low, a phosphatase that converts fructose 2,6-bisphosphate to fructose 6-phosphate, which inhibits PFK.

Glucose can be synthetized in the liver and kidney from lactate (pyruvate), glycerol and amino acids. Muscles differ from the brain in having the bulk of the glycogen store. Fatty acids are the major fuel for the heart and resting muscles. The major fuel for the liver is alpha-ketoacids (e.g., oxaloacetic acid) derived from amino acids.

Leptin suppresses food intake and permits energy expenditure. This hormone is produced from adipose tissue in proportion to fat stores. Circulating LRb, the functional leptin receptor isoform, is highest in the hypothalamus ${ }^{19}$. Leptin binding to LRb activates "LRb-associated Jak2 tyrosine kinase", resulting in phosphorylation of several tyrosine residues (pY) on Jak2 and the intracellular tail of LRb (Y1138, Y1077, and Y985). pY1138 recruits STAT3 (signal transducer and activator of transcription), which stimulates pro-opiomelanocortin (POMC) and suppresses cytokine signaling 3 (SOCS3). pY1077 recruits STAT5. pY985 recruits the tyrosine phosphatase SHP-2, which binds to SOCS3 and mediates the feedback inhibition of LRb signaling ${ }^{20}$.

\section{Conclusion}

This minireview provided principles that govern impaired cellular glucose bioenergetics as a result of childhood obesity, dyslipidemia, diabetes, and hypoglycemia. It is timely considering the current pandemics of obesity, cardiovascular, and metabolic diseases.

\section{References}

1. Kêkê LM, Samouda H, Jacobs J, et al. Body mass index and childhood obesity classification systems: A comparison of the French, International Obesity Task Force (IOTF) and World Health Organization (WHO) references. Rev Epidemiol Sante Publique. 2015; 63: 173-182.

2. Aburawi EH, Al Hamad S, Yasin J, et al. Dyslipidemia, subclinical inflammation, hepatic cholestasis and endothelial dysfunction in schoolchildren with excess fat: A study from the United Arab Emirates. PLoS One 2019; 14: e0210316.

3. AlBlooshi A, Shaban S, AlTunaiji M, et al. Increasing obesity rates in school children in United Arab Emirates. Obes Sci Pract. 2016; 2: 196-202.

4. Magge SN, Goodman E, Armstrong SC. Committee on Nutrition; Section on Endocrinology; Section on Obesity. The metabolic syndrome in children and adolescents: shifting the focus to cardiometabolic risk factor clustering. Pediatrics. 2017; 140(2).

5. Higgins V, Adeli K. Pediatric metabolic syndrome: pathophysiology and laboratory assessment. EJIFCC (Electronic Journal of the International Federation of Clinical Chemistry). 2017; 28: 25-42.

6. Górowska-Kowolik K, Chobot A. The role of gut micorbiome in obesity and diabetes. World J Pediatr. 2019; 15: 332-340.

7. US Preventive Services Task Force, Bibbins-Domingo K, Grossman DC, Curry SJ, et al. Screening for lipid disorders in children and adolescents: US Preventive Services Task Force (USPSTF) recommendation statement. JAMA. 2016; 316: 625-633.

8. Wolfsdorf JI, Glaser N, Agus M, et al. ISPAD Clinical Practice Consensus Guidelines 2018: Diabetic ketoacidosis and the hyperglycemic hyperosmolar state. Pediatr. Diabetes. 2018; 19 Suppl 27: 155-177.

9. Sweet CB, Grayson S, Polak M. Management strategies for neonatal hypoglycemia. J Pediatr Pharmacol Ther. 2013; 18: 199-208.

10. Pierce M, Madison L. Evaluation and initial management of hypopituitarism. Pediatr Rev. 2016; 37: 370-376.

11. Thompson-Branch A, Havranek T. Neonatal hypoglycemia. Pediatr Rev. 2017; 38: 147-157.

12. Thornton PS, Stanley CA, De Leon DD, et al. Pediatric Endocrine Society. Recommendations from the Pediatric Endocrine Society for evaluation and management of persistent hypoglycemia in neonates, infants, and children. J Pediatr. 2015; 167: 238-245.

13. Ichai C, Fenouil E, Grimaud D. Osmolality and brain. Ann Fr Anesth Reanim. 1994; 13: 68-79.

14. Münzberg $H$, Morrison $C$ D. Structure, production and signaling of leptin. Metabolism. 2015; 64: 13-23.

15. Myers MG, Cowley MA, Unzberg HM. Mechanisms of Leptin Action and Leptin Resistance. Annu Rev Physiol. 2008; 70: 537-56.

16. Cunningham SA, Kramer MR, Narayan KM. Incidence of childhood obesity in the United States. N Engl J Med. 2014; 370: 1660-1.

17. Expert panel on integrated guidelines for cardiovascular health and risk reduction in children and adolescents: summary report. Pediatrics. 2011; 128 Suppl 5: S213-56.

18. Simon GR, Baker CN, Barden GA, et al. 2016 recommendations for preventive pediatric health care. Pediatrics. 2016; 137: 25-27.

19. Styne DM, Arslanian SA, Connor EL, et al. Pediatric Obesity-Assessment, Treatment, and Prevention: An Endocrine Society Clinical Practice Guideline. J Clin Endocrinol Metab. 2017; 102: 709-757.

20. Trust for America's Health. The State of Obesity: Better Policies for a Healthier America. Washington, DC: Trust for America's Health; 2019. https://www.tfah.org/wp-content/uploads/2018/09/TFAH-2018ObesityReport-FINAL.pdf. Accessed Janaury 18, 2020. 